that always is assuming that the barometer has fallen in exact accordance to what it was when it was on the ground; whereas it may have risen or fallen in that particular spot which was attained. So the kites ought to be really more valuable in that way, because you know the length of the string you have out and the angle at which it is, therefore you know the height at which it is flying. Would Mr. Harding like to make any reply?

Mr. Handina: With reference to the remarks of Dr. Scott, did he wish me to say Mr. Rush ?

Dr. Scott : Mr. Welsh.

The Chairman: There are two series, I know; one by Mr. Rush and one by Mr. Welsh.

Mr. Hakding: Welsh only made four ascents, that is why $I$ have not referred to him ; Rush made fifteen. With regard to the remarks about crossing to America, one gentleman remarked that it might be easterly above. I hope aeronauts will not think that a sufficiently good reason to risk their necks to try and get across. They know it is westerly below, and therefore they have no difficulty in keeping near the sea. And in such an expedition 1 hope they would be provided for taking to the sea. Then, Sir, with regard to the little slip which I made, I intentionally did that, and I am very glad it was noticed. I know de Rosier made the first attempt from Paris, but Lunardi made it in an ordinary balloon from this country.

The Charrman : The Honorary Secretary will now read a paper by Professor Zahm on "The Measurement of Air Velocity and I ressure." I dare say jou know Professor Zahrn's name as that of a gentleman who has written some very valuable works on this subject.

\section{The Measurement of Air Velocity and Pressure.}

\section{In Aërodynamic Experiments and The Balloon Anemometer.}

\section{By PROFESSOR A. F. ZAHM.}

For general service in aërodynamic experi. mentation two kinds of anemometer may be useful, one measuring air velocity, the other air pressure. Sometimes the velocity alone is required; again the pressure, either static or impactual, is mainly to be determined.
In either case an accurate and faichful instrument is most desirable. Of course the impact can be calculated from the velocity, and vice versa $\hat{a}$, providing all the data are at hand for computing the density of the moring fluid. But when many exact determinations have to be made, it is well to evade such calculations by choosing the appropriate anemometer; that is to say, a velocity instrument for measuring velocity, and a pressure instrument for measuring pressure, or impact. One thereby saves much labour, and avoids tho errors that may result from misreading the elements of density.

Suppose, for example, that one is finding the head-resistance of various models in terms of the wind-speed, observing the latter by means of a velocity anemometer. The wind-speed may be kept constant throughout the research, but the resistance of any given model will vary day by day, and hour by hour. Every three degrees change of the thermometer, or eight millimetres change of the barometer, will alter the resistance one per cent. Even the variations of moisture may make a perceptible difference. So, in order to compare the resistances obtained at different periods, it is necessary to reduce them all to standard atmospheric conditions. This means a great deal of labour and many unwelcome errors. On the other hand, if a pressure anomometer is employed, all these troubles will bo avoided. So long as its readings are kept constant the resistance of the models must remain constant, no matter how the atmospheric conditions may change. Thus all the observations of an extended research may be compared without reduction. In fact, for impact measurements the pressure anemometer has three distinct advantages: (1) Computations are avoided; (2) readings of temperature, pressure, and saturation are unnecessary, and errors from that source obviated; (B) the anemometer readings and model resistances may be plotted while the experiment is in progress, thus revealing observa. tional errors which may at once be eliminated by taking new readings where required. In a similar way it may be seen that the velocity anemometer has equal advantages in many important investigations.

So the need of two kinds of anemometer is a very real one; and it would be well if they were etandardized to measure accurately to, say, one per cent., throughout a wide runge of velocities. At present no such instruments are offered in the market, though 
possibly some of the types in use could be standardized to that degree of accuracy, particularly the screw, the cup, and the pressure-tube varieties. But thus far the calibration of such instruments has proved difficult and not completely satislactory. Indeed it would be an advantage if the anemometers were free from empirical constants, so as not to require calibration at all.

The present paper treats of the design and use of an anemometer* whose observed indications seem to conform to those computed for it from theory. The data submitted were obtained hurriedly, as incidental to other measurements, but it is hoped they are accurate enough to establish confidence in this type of instrument; for it is easy to construct, convenient to use, adapted to a wide range of velocities, and has no empirical constant.

The anemometer is an adaptation of the Pitot tube, and consists essentially of a may quickly come to rest after any displacement. The one here shown has an inch and a quarter outer pipe, a three-quarter inch inner pipe, each ten feet long and connected by three-quarter inch rubber hose to cups measuring one hundred square centimetres in cross-section. The counterpoised beam responds quickly to the varying impulses of the wind, whereas with quarterinch hose of ten feet in length, the motion is tediously slow, owing to the great viscous resistance of the air in such narrow channels.

Almost any size and form of nozzle will convey the impact perfectly, providing it squarely face the wind. All sizes of pipe, from a lemonade straw to a milk-can show exactly the same pressure. All shapes, cylindrical, conical, hemispherical; all thicknesses of wall give identical results.

But the static nozzle must be designed with some care. It should occupy a part of the tube where the stream-lines are un-

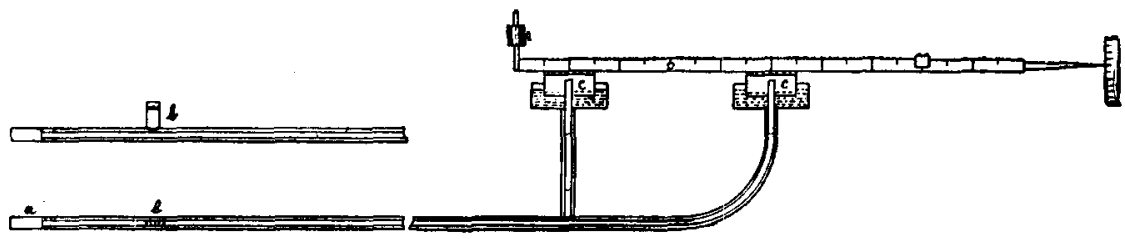

Fig. 1.-The Pressure-Tube Anemometer.

double pressure nozzle in connection with a delicate pressure gauge. The assembled parts are shown in fig. 1 .

A "pressure-tube" held along stream transmits the impact pressure of the uir from nozzle $a$, the static pressure from nozzle $b$, to the cups $c$, of a differential pressure-gauge. These cups, symmetrical in size and placement, are inverted over ccal oil, and counterpoised from a meterstick. A sliding weight, and a pointer, measure the difference between the static and kinetic pressures at the double nozzle; and from this can be computed the speed of the air, if its factors of density are simultaneously observed; that is, its temperature, pressure, and saturation.

We may notice some elements of construction, then the theory and test of the instrument, and finally a few of its applications.

In designing the pressure-tube it is well to select the largest pipe that can be conveniently employed, so that the air within

* This instrument was exhibited before the Washington Philosophical Society, Maj 24, 1902. disturbed, and be so shaped as not to deflect the air blowing over it when the cups are at rest. The nozzle here outlined has two longitudinal slots cut into opposite sides of the outer pipe, one foot from the end, each slot being one-eighth inch wide by three inches long. As will be shown presently, this nozzle seems to give the true static pressure of the passing wind-current.

The cups may be rigidly attached to the beam, or hung like the pans of an ordinary balance. To avoid excessive stability, owing to the buoyancy of the cup walls, it is well to make them of the thinnest metal practicable. For very delicate work it is essential that the liquid flow freely along the cup walls, so as to minimize the effect of surface tension; also the pointer excursion must be limited to a narrow range by suitable stops. If its swing is large the liquid trickling down the cup walls will materially alter the readings, unless a long time is allowed the pointer to come to rest.

The cups here shown have brass walls one hundredth of an inch thick, whose 
effective buoyancy is nearly one per cent. of the pressure on the internal cup base. The coal oil flows freely along their sides, practically eliminating the objection of surface tension. The pointer swings ten millimetres to either side of the zero, the cup displacement being two millimetres. With these limited excursions the trickling of the oil is practically unobjectionable, except for the most delicate measurements. For these, of course, the pointer can be still further limited. The buoyancy, also, is unobjectionable. It is too small to impair the sensibility, and, since its effective lift per unit of surface is precisely equal to that of the air inside the cup, the total lift equals the product of the air pressure by the area of the external base of the cup.

The graduations are found to be convenient in use. The beam is a meter stick carrying a sliding weight and pointer, each of which gives the air pressure in milligrammes per square centimetre, that is to say, in millionths of an atmosphere, approximately. The scale can be made to show less than one tenth of this when the pressure is sufficiently steady, which, however, does not occur in anemometry.

So much for the details of construction and practical operation.

The hydrodynamic principle of the double pressure nozzle is contained in Bernouilli's theorem. For present purposes, however, we may suppose the density of the air constant, its flow uniform and level.

Bernouilli's theorem may then be stated as follows : at all parts of a stream-line the velocity head plus the pressure head equals a constant. Or otherwise :

$$
\frac{s v^{2}}{2 g}+p=p_{0}
$$

in which $s, v, p$, are the density, velocity, and pressure of the fluid at any point of the stream-line, and $p_{0}$ is the pressure due to the total head, or pressure at a point where the velocity is zero. Hence, if the nozzle will measure the differential pressure $p_{0}-p$, we can at once compute $v$ therefrom.

To prove formula (1) let us take the general stream-line equation (Lamb's $\mathrm{Hy}$ drodynamics, p. 25):

$\frac{v_{1}{ }^{2}-v_{2}{ }^{2}}{2 g}=\frac{\gamma}{\gamma-1} \frac{p_{2}}{s_{2}}\left[1-\left(\frac{p_{1}}{p_{2}}\right) \gamma-\frac{1}{\gamma}\right]$

$v, p, s$, being the velocity, pressure, density, at any one point of the stream-line; $v_{2}, p_{2}, s_{2}$, like values at any other point. Let $v_{2}=0$, be the velocity at the impact mouth of the pressure tube, $v_{1}$, the velocity in the unchecked stream, and write $p_{1}=p_{2}(1-x)$. Then the general equation can be written :

$$
\begin{aligned}
\frac{s_{1} v_{1}^{2}}{2 g} & =\frac{\gamma}{\gamma-1} \frac{s_{1}}{s_{2}} p_{2}\left[1-(1-x) \frac{\gamma-1}{\gamma}\right] \\
& =\frac{s_{1}}{s_{2}} p_{2}\left(x-\frac{x_{2}}{2 \gamma}+\frac{1+\gamma}{6 \gamma^{2}} x^{3}-\ldots\right)
\end{aligned}
$$

Now $x=\frac{p_{2}-p_{1}}{p_{2}}$, is usually very small ; its largest value in this research being about 0.001 ; also $\frac{s_{1}}{s_{2}}$ differs from unity by less than 0001 ; and $\gamma=1.408$. Hence the equation reduces to:

$$
\frac{s_{1} v_{1}^{2}}{2 g_{1}} \pm p x=p^{2}-p_{1}
$$

which is true to less than 0.1 per cent. for the range of velocities employed. Or, changing the notation, we have the formula:-

$$
\frac{s v^{2}}{2 g}+p=p_{0}
$$

in which $p$ is the pressure in the unchecked stream, $p_{0}$ the pressure in the impact mouth of the tube.

To demonstrate experimentally that the pressure $p_{0}$ is equal to the total head pressure, the following plan was pursued. A tube two and one-half inches in diameter by eight inches long was inserted into the side of a tunnel in which a partial vacuum was maintained by means of an exhaust fan. A nozzle one-eighth of an inch in diameter, held in the centre of this tube, transmitted the impact of the inrushing air to one cup of the pressure gauge, the other being connected with the quiet part of the tunnel. The gauge reading was taken; then the nozzle was thrust through the inlet tube towards the outside of the tunnel, and finally clear outside. No appreciable change of pressure could be noticed, thus showing that an impact nozzle sustains a constant pressure at all points of a stream-line, and that this is equal to the total head pressure. Again, the impact pressure was read at five different fan speeds, the nozzle being held first in the quiet outer atmosphere, then at the centre of the inlet tube. The readings agreed to less than one per cent., as exhibited by the subjoined table. 
TABLE I.

Comparison of Total Head with Impact Pressure at l'oint of Greatest V'elocity.

\begin{tabular}{|c|c|c|}
\hline Fan Speed. & Total Head. & $\begin{array}{c}\text { Impact Pressure } \\
\text { at Centre of Inlet. }\end{array}$ \\
\hline rev. min. & mg. per sq. cent. & mg. per sq. cent. \\
$150^{\circ}$ & $540^{\circ}$ & $538^{\circ}$ \\
$170^{\circ}$ & $680^{\circ}$ & $678^{\circ}$ \\
$200^{\circ}$ & $850^{\circ}$ & 847.5 \\
$225^{\circ}$ & $1000^{\circ}$ & 997.5 \\
$245^{\circ}$ & $1100^{\circ}$ & $1108^{\circ}$ \\
& & \\
\hline
\end{tabular}

If it could be shown with equal exactness that the side nozzle measures the static pressure of the fluid gliding over it, the theory of the pressure tube would be completely verified. It is easy to measure the actual pressure sustained by the side nozzle at any point of the stream, but not so easy to prove the observed pressure equal to the true static pressure at the point, except where the velocity is zero or a maximum. It is zero where the stream tube is very broad, say, in the reservoir, and here, of course, $p=p_{0}$; it is a maximum where the air rushes freely through the inlet tube, and here the static piessure must, according to theory, be equal to the pressure inside the tunnel. In fact, when a narrow statis tube, held at the centre of a large inlet, was connected with one cup of the gauge, while the other cup was joined by hose to the quiet part of the tunnel, no material difference of pressure was observed. Hence we may conclude that the observed pressure equals the true static pressure for that particular velocity. The experiment was made at five different fan speeds with Jike result.

It thus appears that, for all the velocities employed, which extended from five to thirty miles an hour, the impact nozzle sustains exactly the pressure $p_{\circ}$, the static nozzle the pressure $p$. Hence when the two nozzles $a$, $b$, fig. 1, are connected simultaneously with the pressure-gauge, as is regularly done in practice, their differential pressure $p_{0}-p$ must be an exact measure of the quantity $s v_{2}^{2} g$, and therefore determines the true velocity of the air. Now, by equation (1) $s v^{2}=2 g\left(p_{0}-p\right)$; or writing $k=\sqrt{2 g 1 s}$, $\delta=p_{0}-p$, the velocity is :

$$
v=k \sqrt{\delta} \text {. . (2). }
$$

In practice the differential pressure, $\delta$, is read directly from the instrument in milligrammes per square centimetre, and $k$ is computed from the observed elements of density. Thus for dry air at $0^{\circ}$ Centigrade, and a megadyne per square centimetre pressure, $s=1 \cdot 2759$ grammes per litre, hence $k=\sqrt{2 \times 980.95 \div 1.2759}$ $=39 \cdot 21$ for the latitude of Washington; and the velocity in centimetres per second is :

$$
v=39 \cdot 21 \sqrt{\delta} \text {. }
$$

For air at any temperature, pressure, and humidity (Minchin's Hydromechanies), the density is :

$$
s=0.4645(8 p-3 f) \div 8 T ;
$$

$p$ being the barometric pressure in millimetres, $f$ the aqueous vapour pressure, $T$ the absolute temperaturs Centigrade. From this, $k$ can be computed for any observed atmospheric conditions.

As a further test of the accuracy of the pressure-tube anemometer, its readings were compared with those of another instrument, designed with a special view to precision rather than convenience. Ten observations of the wind speed were taken simultaneously with both anemometers, and their average values agreed to less than one per cent. This extra instrument, which is sometimes used to standardize others, may be called the balloon anemometer. A brief description of its plan and performance may be worth a passing notice.

A toy balloon is held at the centre of the wind-tunnel, between the prongs of a fork, one prong being firmly moored to the wall by a thread, the others joined to a release string. When the string is jerked the fork spreads and the balloon floats along the wind-current without rotation. After drif ing less than eight feet it has acquired the full velocity of the wind, as may be proved by projecting the balloon with like speed in still air, and observing how far it moves before coming practically to rest.

To find the velocity of the balloon two thin pencils of light are thrown squarely across its path, and the time of transit recorded by a camera designed for that purpose. The general plan of the apparatus is shown in fig. 2.

A bank of incandescent lamps, $a, a$, shining through $\frac{1}{8}$-inch holes in the tunnel wall, are brought to focus on a very sensitive photographic plate $b$. Ten feet farther along the tunnel a like thing occurs. The plates are clamped to a 10-foot board, which is drawn by hand along grooves inside the camera box, the box itself being 13 feet long. The images of the incandescent carbons trace, along each plate, fine straight lines, which are momentarily interrupted by the passing balloon. 
The method is an adaptation of that used by the writer to measure the velocity of projectiles.*

To time the plate, an electric tuning-fork interrupts one of the light beams 128 times a second, making the record a dotted line. After development, the plate records are superposed, and the number of vibrations counted from centre to centre of corresponding balloon breaks. This gives the time of transit of the balloon over the 10-foot stage, from centre to centre of the light screens, and thereby determines the wind velocity. The duration of transit is revealed accurately to less than one part in five hundred. For greater exactness the circuit is broken, and the fork vibrates freely during the balloon flight.

The accompanying table gives the data for ten observations at practically the same wind velocity. Measurements were not made at other speeds for lack of time.

TABLE II. Comparison of Balloon Flight and Pressure" tube Readings. Barometer, 746.5் m.m.; Temperature, $284^{\circ}$ C.; Saturation, 50 .

\begin{tabular}{|c|c|c|c|}
\hline \multirow{2}{*}{$\begin{array}{c}\text { Pressure- } \\
\text { tube } \\
\text { Readinge. }\end{array}$} & \multirow{2}{*}{$\begin{array}{l}\text { Tuning-fork } \\
\text { Vibrations. }\end{array}$} & \multicolumn{2}{|c|}{$\begin{array}{c}\text { Velocity of Wind in } \\
\text { Tunnel. }\end{array}$} \\
\hline & & $\begin{array}{l}\text { By Pres- } \\
\text { sure-tube. }\end{array}$ & $\underset{\text { Balloon. }}{\text { By }}$ \\
\hline $\begin{array}{c}\text { Mg. per } \\
\text { Sq. Cm. } \\
365 \\
36 \\
36 \\
36 \cdot 5 \\
39 \cdot 5 \\
37 \cdot 25 \\
36 \\
36 \cdot 5 \\
36 \cdot 5 \\
38 \cdot 5\end{array}$ & $\begin{array}{l}163 \cdot 5 \\
162 \cdot 3 \\
163 \cdot 5 \\
166 \\
157 \cdot 4 \\
156 \cdot 2 \\
156 \cdot 8 \\
157 \cdot 8 \\
171 \cdot 3 \\
161\end{array}$ & $\begin{array}{c}\text { Ft. Sec. } \\
7 \cdot 96 \\
7 \cdot 90 \\
7 \cdot 90 \\
7 \cdot 96 \\
8.27 \\
8 \cdot 03 \\
7 \cdot 90 \\
7 \cdot 96 \\
7 \cdot 96 \\
8 \cdot 16\end{array}$ & $\begin{array}{c}\text { Ft. Sec. } \\
7 \cdot 85 \\
7 \cdot 90 \\
7 \cdot 85 \\
7 \cdot 73 \\
8 \cdot 16 \\
8 \cdot 20 \\
8 \cdot 18 \\
8 \cdot 12 \\
7 \cdot 50 \\
7 \cdot 96\end{array}$ \\
\hline & & Mn. 8.00 & Mn. 7.95 \\
\hline
\end{tabular}

* "Resistance of the Air at Speeds Below One Tbousand Feet a Second," Philosophical Magazine, May, 1901 .
The results show that the average air velocities, as determined by two such widely different instruments, agree to less tban

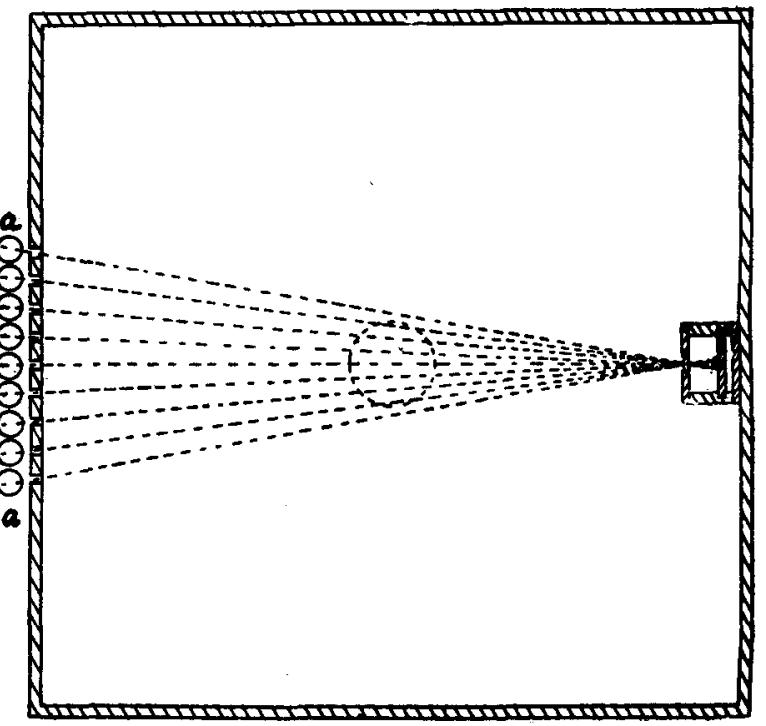

Fig. 2.-The Balloon Anemometer.

1 per cent. The coincidence is rather too close to be representative; still, the general agreement is such as to establish confidence in this form of pressure-tube anemometer, at least for the velocity at which the test was made. To assure ourselves that the instrument is reliable at other velocities, we may recall the experimental proof that each nozzle sustains exactly the theoretical pressure at all speeds to 30 miles an hour.

Incidentally, in the course of other researches, this anemometer has been com. pared with several instruments of a different type; notably two cup anemometers, a large and a small one, used by the United States Weather Bureau; a screw, and a cup anemometer employed at the Smith. sonian Institution; and a Dines pressuretube anemometer.

The following page from the laboratory note-book illustrates the calibration of the first instrument mentioned. It was placed in the tunnel beside the pressure-tube in such a way that neither interfered with the other. The time of fifty revolutions of the cups was indicated by an electric bell, and the interval between two, or more, ringings of the bell was measured by means of a stop watch reading to quarter seconds. The readings of the pressure gauge were simultaneously noted. 
Table III.

Comparison of Standard Pressure-Tube Anemometer and Four-Inch Cup Anemometer of the U.S. Weather Bureau. Barometer $30^{\prime \prime} \cdot 473$; thermometer $3^{\circ} \cdot 5 \mathrm{C}$.

\begin{tabular}{|c|c|c|c|c|c|}
\hline Date. & Fan. & $\begin{array}{c}\text { Pressure- } \\
\text { Tube. }\end{array}$ & $\begin{array}{c}\text { Wind } \\
\text { Speed. }\end{array}$ & $\begin{array}{c}4^{\prime \prime} \mathrm{Cup} \\
\text { Ane- } \\
\text { mometer. }\end{array}$ & $\begin{array}{l}\text { Wind } \\
\text { Speed. }\end{array}$ \\
\hline $\begin{array}{c}\text { Feb. } 20 \\
1903 . \\
\text { 2.15 p.n }\end{array}$ & $\begin{array}{l}\text { rev. } \\
\text { min. } \\
150 \\
200 \\
250 \\
300 \\
350 \\
400 \\
450\end{array}$ & $\begin{array}{c}\text { mg. sq. } \\
\text { cm. } \\
\mathbf{4 3} \\
89 \\
120 \\
180 \\
250 \\
295 \\
350\end{array}$ & $\begin{array}{c}\text { mi. hr. } \\
5 \cdot 7 \\
7 \cdot 9 \\
95 \\
11 \cdot 7 \\
13 \cdot 7 \\
15.0 \\
16.2\end{array}$ & $\begin{array}{c}\text { sec. in } 50 \\
\text { rev. } \\
62 \cdot 5 \\
44 \cdot 5 \\
35 \cdot 5 \\
29 \cdot 0 \\
23 \cdot 5 \\
22 \cdot 0 \\
39 \cdot 6\end{array}$ & $\begin{array}{c}\text { mi. hr. } \\
5 \cdot 8 \\
79 \\
9 \cdot 7 \\
11 \cdot 7 \\
14 \cdot 0 \\
14 \cdot 9 \\
16 \cdot 5\end{array}$ \\
\hline
\end{tabular}

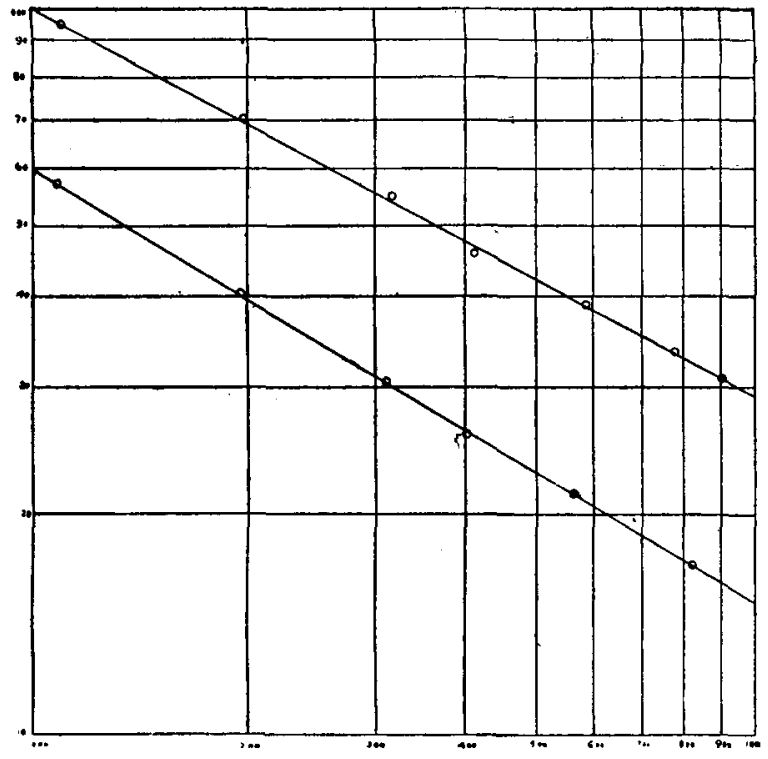

Fig. 3.-Calibration Diagram of Smithsonian Anemometers.

Abscissae = Standard Pressure - Tube Readings in mg. sq. cm.

Ordinates $=$ Corresponding Readings of Bmithsonian Anemometers. Cup Anemometer Diagram below; Sorew-Anemometer Diagram above.

By comparing the wind velocities indicated by these two instruments it will be seen that they differ by less than 2 per cent. This is the case under favourable circumstances, when due attention is given to the working condition of the instruments ; but, if they are not very carefully used, the discrepancy may exceed 5 to 10 per cent. of the quantity measured.

In a similar way the calibration of the small Weather Bureau instrument, known as a kite anemometer, having cups one inch in diameter, and four inches from centre to centre, gave the following values :-
TABLE IV.

Comparison of Standard Pressure-Tube Anemometer and One-Inch Cup Anemometer of the U.S. Weather Bureau.

\begin{tabular}{|c|c|c|c|c|c|}
\hline Date. & Fan. & $\begin{array}{c}\text { Pressure- } \\
\text { Tube. }\end{array}$ & $\begin{array}{l}\text { Wind } \\
\text { Speed. }\end{array}$ & $\begin{array}{l}\text { Cup Ane- } \\
\text { mometer. }\end{array}$ & $\begin{array}{l}\text { Wind } \\
\text { Speed. }\end{array}$ \\
\hline $\begin{array}{c}\text { Jan. } 3, \\
1903 . \\
2.25 \mathrm{p.m}\end{array}$ & $\begin{array}{l}\text { rev. } \\
\text { min. } \\
200 \\
300 \\
400 \\
500 \\
600\end{array}$ & $\begin{array}{c}\text { mg. sq. } \\
\text { cm. } \\
110 \\
220 \\
370 \\
570 \\
830\end{array}$ & $\begin{array}{c}\mathrm{mi} . \mathrm{hr} . \\
9.53 \\
13.46 \\
17.46 \\
21.68 \\
26.14\end{array}$ & \begin{tabular}{|} 
sec. in 500 \\
rev. \\
$121 \cdot 25$ \\
$83^{\prime}$ \\
$65^{\circ}$ \\
51. \\
41.5
\end{tabular} & $\begin{array}{c}\text { mi. hr. } \\
9.45 \\
13.8 \\
17 \cdot 55 \\
22.35 \\
27 \cdot 4\end{array}$ \\
\hline
\end{tabular}

The results obtained in standardizing the anemometers of the Smithsonian Institution are given diagrammatically to show the concordance of the observations. They were obtained in less than an hour for each instrument, without special pains; yet the data seem to harmonize very well, and to ind1cate that such instruments may give quite accurate readings when used with due care. One is a cup anemometer having cups one inch in diameter, and three and three eighths of an inch from centre to centre; the other is a Beck screw anemometer, two and five eighths of an inch in diameter, and having flat blades. The data are plotted on logarithmetic cross - section paper for convenience, their relation being expressed by a straight line in such co-ordination.

Very interesting results were obtained from the pressure - tube anemometer invented by $\mathrm{Mr}$. W. H. Dines, Fellow of the Royal Meteoro. logical Society of England. This instrument is manufactured by Cassella, of London, and is extensively used, in one form or another, throughout Great Britain and on the Continent, notably in the meteorological service. The essential difference in principle between the Dines pressure-tube and mine consists in the form of the static nozzle, which in his instrument is a punctured dome whose axis is at right angles to the stream-lines, while in mine it is a hole, or slot, so placed as not to deflect the stream-lines.

In order to compare the two instruments, the Dines static nozzle was employed as shown in fig. $1, b^{1}$, and readings taken at several different fan speeds. Then similar 
readings were taken with the pressure tube shown in fig. $1, b$, under the same weather conditions. The results are presented in the accompanying table, and plotted to the same scale on logarithmic cross-section paper, as shown in fig. 4 .

$$
\text { TABLE V. }
$$

Comparison of Stream-Line Static Nozzle with Dines' Nozzle.

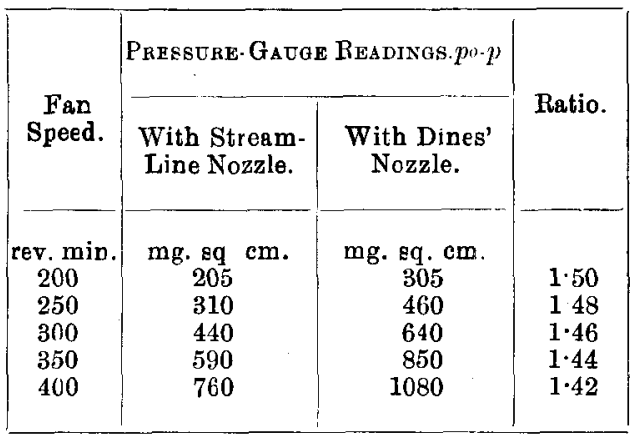

The readings obtained with the Dines nozzle are approximately 1.46 times those found with the stream-line nozzle, for the velocities employed, which ranged from ten to twenty-five miles an hour. This excess is doubtless due to the suction in the rear of the punctured dome which constitutes his static nozzle. The dome, therefore, possesses the advantage of magnifying

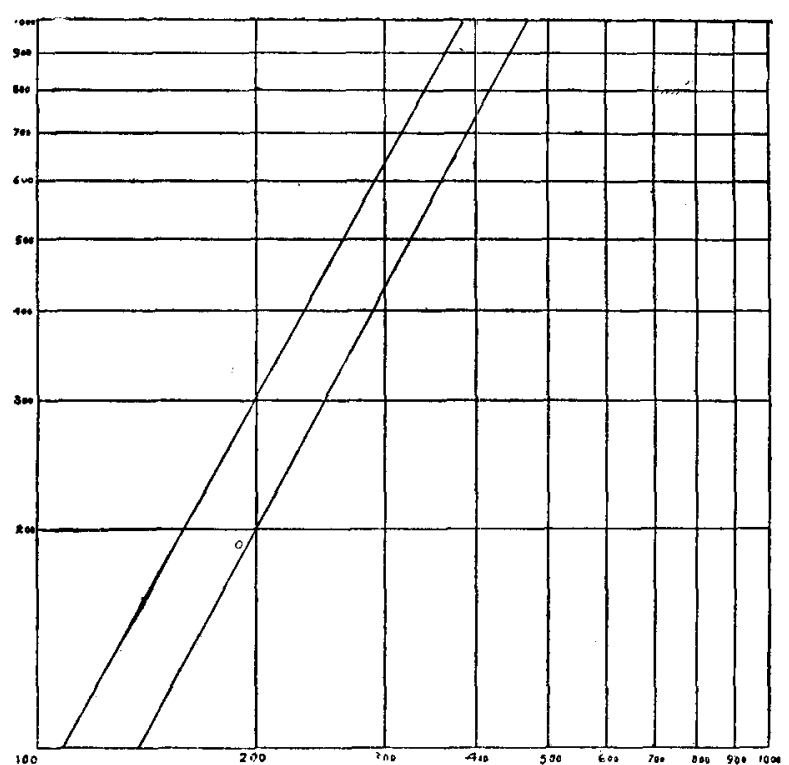

Fig. 4--Comparison of Stream-Line Nozzle with Dines' Nozzle.

Abscissae = Revolutions of Fan per minute.

Ordinates $=$ Reading $s$ of the Two Anemometers in mg. \&q. cm. the readings of the instrument. Its liydrodynamic theory, however, is different from that of the stream-line nozzle, and its readings cannot be calculated from equation (2) of this paper.

It would be interesting to find a theoretical formula that would give, for Dines' instrument, the exact relation between the wind velocity and the differential pressure. For the range of velocities shown in Table

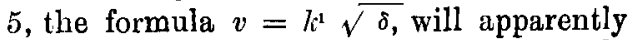
give the true wind speed, if $1.46 k^{1}$ equals $k$ of formula (2). But the comparison was too briefly made to be conclusive. Besides, the formula thus obtained is only an ap. proximate one, and does not free the instrument from an empirical constant.

Various otber forms of static nozzle have been used by different experimenters. The simplest of these is a straight, openended tube, standing at right angles to the current. Another form consists of two thin circular discs, placed very near together, their axis perpendicular to the current ; and in the modification used by Professor Nipher, a sheet of wire gauze fills the space betwetn the discs, protruding slightly beyond their edges. Neither of these nozzles, however, bas been compared with the one discussed in this paper.

I would refer the reader interested in the pressure-tube, as an instrument for measuring the velocity of liquids, to a very careful and valuable paper by $\mathrm{Mr}$. W. M. White, read before the Louisiana Engineering Society, May 13, 1901 , and published in the "Journal of Engineering Societies" the following August. His methods of experimentation were quite different from the ones here outlined, but they established conclusively the theory of the pressure nozzle for water. Indeed this is as it should be, since the equation of motion is the same in both caser. Thus the two researches corroborate one another, if the excellent work of Mr. White can be said to need any confirmation.

In conclusion, it is a pleasure to acknowledge my indebtedness to Mr. D. W. Taylor, Naval Construetor U.S.N., for his kind interest in this work. Indeed it was at his suggestion that the present investigation was taken up. He was making, for the Government, a 
study of the ventilation of ships, with a view to determining the efficiency of different fans, and the most favourable working conditions of the ventilating system. He relied upon the Pitot tube to determine the flow of air at various points of the ventilating pipes, and, in October, 1902, expressed the wish to have its accuracy tested in a wind current of known velocity. This led to the device which I have described as the "balloon anemometer." The apparatus was made, and the observations were taken in November, 1902.

I have also to thank Professor C. F. Marvin, of the Weather Bureau, and Mr. C. M. Manly, of the Smithsonian Institation, for many valuable suggestions, for the use of a variety of anemometers, and for the important literature and references pertaining to this work.

The Chairman : This is evidently a very important paper in its particalar line. It is rather a confined subject, which we do not all thoroughly go into, and it is rather difficult to understand some of the observations when we have not the actual instruments before us. But, no doubt, those who are making a study of anemometers will be much interested in some of the detuils given. I may mention, incidentally, whilst we are referring to Professor $\mathrm{Zahm}$, that I received the other day from him a very valuable pamphlet on skin friction, which had some very important results for those who are studying aërodynamics, in that hitherto the experiments of Langley and Maxim tended to prove that skin friction was quite negligible in air currents. But Professor Zahm -you see from the paper the method he has of going into details-has made a series of experiments which prove that the skin friction of the air on inclined surfaces is a very important consideration. That is a subject we will go into afterwards, but I thought $I$ would just mention it, in connection with his name. As time is going on we will get on with the next paper on "Air Tight Balloons," by Messrs. Short.

\section{An Airtight Balloon Car for High Ascents.}

BY MESSRS. EUSTACE SHORT AND HORACE LEONARD SHORT.

It gives us great pleasure to have this opportunity of submitting and explaining to you a specially constructed airtight car which we have designed for the purpose of reaching high altitudes.

In the past many attempts have been made to reach great heights in open cars for the purpose of making scientific observations and experiments, and from these experiments it appears that the only difficulty which has been grappled with is that of the insufficiency of air for respiration purposes. To overcome this difficulty the general plan has been to take up in bags or other receptacles a supply of oxygen.

As no attempt, however, has been made to overcome the great inconvenience suffered by the occupants of the balloon, due to the exceedingly low pressure at these high altitudes, these many attempts, in spite of the oxygen supply taken, have been fraught with great inconvenience and danger.

The car about to be explained is designed for the express purpose of overcoming both of the aforesaid difficulties, and by carrying up a sufficient supply of air, maintained at the necessary pressure, it will enable persons to ascend without experiencing any great inconvenience, and with all their faoulties clear to take observations and make experiments.

Of course there is another thing to be considered when it is desired to ascend to great heights, and that is the necessary size or capacity of the balloon. It is not necessary here to enter into this question closely, and it may be sufficient to give an approximate outline of the general features desirable for attaining this object.

Assuming the balloon is required to take the car to a height of 11 miles, where the air is approximately only one-eighth the density of that at the surface of the earth, the balloon must be able to raise itself and its complete equipment when oniy oneeighth part full, so as to allow for expansion without loss.

The car which forms the main subject of this paper is designed to carry three persons. Its computed weight approximates $500 \mathrm{lbs}$. , and the computed weight of the envelope of the balloon, together with its complete equipment, apart from the passengers and instruments, approximate 3,300 lbs. To this must be added the weight of the three passengers, which, taken at $150 \mathrm{lbs}$. each, gives $450 \mathrm{lbs}$., say $40 \mathrm{lbs}$. for instruments, and ballast to be reserved for landing purposes, 780 lbs.

This gives a total weight of $5,070 \mathrm{lbs}$. to be raised from the ground, when the balloon is only one-eighth part inflated, and there- 